\title{
Frankenstein e o clima organizacional: Estudo bibliográfico sobre um construto indefinido
}

\author{
Frankenstein and organizational climate: Bibliographic study on an indefinite \\ construct
}

\section{Edson Keyso de Miranda Kuboํㅜ, Denise Gutierrez Castro², Vinicius Domingues Nunes ${ }^{3}$ e Fernando Thiago 4}

Resumo: Estudo bibliográfico acerca do clima organizacional, que se constitui como um construto de ampla utilização em gestão de pessoas. O clima tem sido abordado de várias maneiras, com inúmeras definições e modelos que o explicam, não havendo consenso sobre sua definição $e$ mensuração. Este artigo objetiva reunir pesquisas sobre Clima Organizacional, apresentando suas divergências teóricas à ótica de autores que contribuíram para sua criação, buscando evidências sobre os motivos das diferenças existentes entre suas abordagens. Como resultado, observam-se as divergências marcantes e necessárias entre os critérios que compõem o construto, por contemplar a necessidade de incluir a percepção de politicas e práticas organizacionais. Tratase, portanto de um construto moldado que remete à ideia da criatura de Shelley (2012), formada por pedaços distintos de outras criaturas e sem um núcleo determinado, que garanta uma existência plena, permitindo assim a relação metafórica como o monstro de Frankenstein.

Palavras- chave: Clima Organizacional, Diagnóstico organizacional, Modelos de Clima.

Abstract: Bibliographic research about the organizational climate, which constitutes a construct of wide use in People Management. The climate has been approached in many ways, with many definitions and models that explain it and there is no consensus on its definition and measurement. This article aims to bring together research on Organizational Climate, presenting the theoretical divergences of the authors who contributed to its creation, seeking evidence on reasons for existing differences between their approaches. As a result, one can find the remarkable and necessary differences between the criteria that make up the construct, since it contemplates the need to include the perception of organizational policies and practices. It is therefore a construct that refers to the idea shaped Shelley (2012)'s creature, formed by separate pieces of other creatures and without a certain core that ensures full existence, thus allowing the metaphorical relationship to Frankenstein's monster.

Keywords: Organizational Climate, Organizational Diagnosis, Climate models.

1 Universidade Municipal de São Caetano do Sul (USCS), Brasil. E-mail: edsonkubo@uscs.edu.br

2 Universidade Municipal de São Caetano do Sul (USCS) e Técnica da Universidade Federal do Grande ABC (UFABC), Brasil. E-mail: denisegcastro@gmail.com

3 Universidade Municipal de São Caetano do Sul (USCS), Brasil. E-mail: vinicius.d.nunes@gmail.com

4 Universidade Municipal de São Caetano do Sul (USCS) e Técnico da Universidade do Estado de Mato Grosso (UNEMAT), Brasil. E-mail: admfernandoth@uscs.edu.br

Recibido: 14/11/2014; Aceptado: 27/05/2015.

http://dx.doi.org/10.18004/riics.2015.julio.35-54 


\section{INTRODUÇÃO}

O construto de Clima Organizacional é reconhecidamente um instrumento composto de diversas abordagens na área de Gestão de Pessoas e tem sido amplamente utilizado como ferramenta de diagnóstico organizacional. São vários os modelos e conceitos a respeito do clima e sua relevância se deve ao fato de abordar o ambiente interno de trabalho. Nesse sentido, as influências do ambiente interno sobre o comportamento humano são inerentes aos estudos do Clima Organizacional, sendo importante determinar como as pessoas denotam seu ambiente de trabalho a partir dos estímulos proporcionados pela organização. Diante desse diagnóstico, torna-se possivel intervir para se obter melhores condições de trabalho $\mathrm{e}$ desempenho a partir de um adequado Clima Organizacional.

Desde seu surgimento, uma série de divergências entre conceitos e dimensões sobre este tema tem se manifestado na literatura, não sendo essa uma novidade quando se tratam de temas que possuem como característica a inexistência de uma teoria única como pilar. O campo teórico sobre esse construto é difuso e complexo, sujeito a contradições e falta de consenso quanto à sua definição e seus fatores constituintes. A esse respeito, compartilham desta visão diversos autores, tais como Patterson, 2005; Bispo, 2006; Puente-Palacios e Freitas, 2006; Thumim e Thumim, 2011; Schneider, Ehrhart e Macey, 2012; Bernstrøm, Lone, Bjørkli, Ulleberg e Hoff, 2013, Peña-Suares, Muñiz, Campillo-Álvarez, Fonseca-Pedrero e García-Cueto, 2013; e Rocha, Pelogio e Añez, 2013.

Observa-se que pesquisas e diagnósticos referentes ao Clima Organizacional se somam a outros construtos de acordo com a necessidade e a peculiaridade de cada objeto de pesquisa, que neste caso é representado pelas organizações, permitindo assim um retrato a partir de um corte temporal para ações gerenciais pontuais.

Sob esse contexto, este artigo objetiva a analisar a produção acadêmica sobre o Clima Organizacional, apresentando suas divergências teóricas endógenas e particulares à ótica de cada autor que contribuiu para sua criação, por meio de uma pesquisa bibliográfica (Gil, 2009) buscando evidências sobre os motivos das diferenças existentes entre as abordagens desses autores.

As indagações que motivaram este artigo estão nas raízes do próprio construto, que contempla e indica diversidade e falta de consenso para sua mensuração, assim como apropriação e amalgamação de outros construtos importantes da Gestão de Pessoas (GP). Almeja-se, assim, contribuir teoricamente para esclarecer e fundamentar o clima organizacional enquanto construto, que se mostra disforme e concomitantemente necessário para a GP. 
Este artigo se propõe a buscar a definição das partes do Clima Organizacional. Contudo, enquanto seu todo não se define como uno, o construto se torna uma soma de partes, assim como o monstro de Frankenstein descrito por Shelley (2012), em que a criação carece de um propósito definido e de uma junção formal que a torne mais do que as somas das partes de outros, por definição de seu criador.

O Monstro de Frankenstein, criatura formada a partir de cadáveres humanos e transformada pelo Dr. Victor Frankenstein, é comumente conhecida na ficção romântica como a criatura trágica, que foi considerada por seu mestre como uma aberração, um ser não natural, que desafia a própria existência. Shelley (2012) compôs esta obra em 1818, um momento em que a construção científica se exaltava, comparando-se ao passado e em direção a rumos sem precedentes.

A discussão trazida por Shelley (2012), dentre outros diversos temas, como a amizade e a evolução científica, traz em sua essência o existencialismo de uma criatura que, embora seja viva, é uma construção desprovida de unidade e de propósito contestável e busca a própria razão de ser por meio de seu criador.

A construção do Clima Organizacional como construto se difere, em parte, da criatura de Victor Frankenstein. Isso é devido ao fato de não ter surgido a partir da individualidade de um criador, mas de muitos. Contudo, esta mesma característica permite que o conceito teórico possa se assemelhar mais à criatura ficcional, pois engendra a capacidade de ser compostas por partes preexistentes e rearranjadas em uma nova forma.

Assim, este artigo trata metaforicamente de um construto que também possui diversidade em suas partes constituintes, apesar de seus diversos criadores e pesquisadores nunca encontrarem uma teoria base que o sustentasse. O Clima Organizacional se mantém disperso entre ideias que em alguns momentos convergem em razões primárias de sua existência, entretanto, em outros divergem em elementos advindos de sua gênese. Portanto, a metáfora se faz entre esse construto utilizado pela GP, que não possui o núcleo definido e a criatura que procura por sua razão de ser.

Este artigo é estudo bibliográfico que se utilizou de uma metodologia denominada pesquisa bibliográfica, por contemplar a análise de pesquisas sobre clima desde a década de 70 até os dias atuais. De acordo com Gil (2009), a pesquisa bibliográfica envolve a investigação de artigos, publicações, livros sobre temas que precedem a pesquisa de campo.

Trata-se de uma reflexão crítica sobre os assuntos estudados, analisando controvérsias, identificando teorias de relevância para o fenômeno de interesse, a 
partir de publicações científicas como teses, dissertações, artigos publicados em periódicos científicos, etc. (Gil, 2009).

Os resultados foram analisados, confrontados e objetivou-se a busca de padrões de explicação ou mesmo lacunas não resolvidas nessas literaturas acerca do Clima Organizacional. Por se tratar de um tema relevante ainda hoje, justifica-se a pesquisa bibliográfica pelo fato de não haver consenso e mesmo uniformidade na definição e operacionalização do clima, que continua a ser um tema de fronteira em Gestão de Pessoas.

Para tanto, além da seleção de publicações para formatação da revisão teórica, foram selecionados trabalhos nacionais em periódicos revisados por pares e um trabalho publicado em uma coletânea de escalas para mensuração do comportamento organizacional. Além disso, a utilização de metáforas no ambiente científico para explicação de fenômenos é relevante. Segundo Cornelissen, Oswick, Christensen e Phillips (2008), essa prática pode ser o primeiro passo para um processo de analogia, trabalhado em isomorfismos que podem resultar em teorias científicas. Para Bloom (1996), como citado em Islan (2011), a utilização de metáforas não é responsável diretamente pela teorização literal, mas permite uma visão indireta de um "reino intermediário" que se perdeu na percepção direta.

O próprio tema de pesquisa originou-se de um processo metafórico ao criar a analogia do clima provindo da área da meteorologia (Puente-Palacios e Freitas, 2006) sendo necessário inicialmente para uma melhor compreensão e elaboração desse construto.

Este artigo está organizado do seguinte modo, primeiramente após essa introdução é apresentada a seção de formação do Clima Organizacional enquanto construto, mostrando sua diversidade e amplitude; após isso, apresentam-se as escalas de Clima Organizacional e discute-se a redundância e abrangência de suas dimensões e fatores e, na sequência, as considerações finais.

\section{METODOLOGIA}

Esse artigo se utilizou de uma pesquisa qualitativa cuja metodologia foi baseada em uma pesquisa bibliográfica. A abordagem qualitativa é pertinente quando se pretende compreender um fenômeno social e não empregar métodos estatísticos para análise (Denzin e Lincoln, 2006). De acordo com Gil (2009), a pesquisa bibliográfica é adequada em pesquisas exploratórias, por meio da análise de trabalhos já publicados, envolvendo teses, dissertações e artigos científicos. Por meio da análise desses trabalhos é possivel verificar as tendências dos temas, suas 
abordagens mais comuns e convergências e divergências das conclusões dos autores. Houve portanto um levantamento acerca da produção científica envolvendo o Clima Organizacional, que resultou na tabela 1.

Tabela 1. Quantificação dos trabalhos sobre clima organizacional.

\begin{tabular}{|c|c|c|}
\hline Autores & $\begin{array}{l}\text { Tema dos } \\
\text { Trabalhos }\end{array}$ & $\begin{array}{r}\text { Quant. temas } \\
\text { acumulado }\end{array}$ \\
\hline Asif (2011). & Cultura e Clima & 1 \\
\hline Bernstrøm et al. (2013) & Pesquisa de Clima & 1 \\
\hline Bispo (2006) & Pesquisa de Clima & 2 \\
\hline Coda (1993) & Pesquisa de Clima & 3 \\
\hline Del Campo (2013). & Pesquisa de Clima & 4 \\
\hline Imran, Saeed, Anis-Ul-Haq e Fatima (2010) & Clima e Inovação & 1 \\
\hline Koles e Kondath (2015) & Cultura e Clima & 2 \\
\hline Koys e Decotiis (1991) & Pesquisa de Clima & 5 \\
\hline Martins (2008) & Pesquisa de Clima & 6 \\
\hline Nakata, Veloso, Fischer e Dutra (2009) & Pesquisas de Clima & 7 \\
\hline Oliva, Falchi e Falchi (2007) & Pesquisa do Clima & 8 \\
\hline Patterson et al. (2005) & Pesquisa de Clima & 9 \\
\hline Peña-Suares et al. (2013) & Pesquisa de Clima & 10 \\
\hline Pimenta, El Aouar e Oliveira (2012) & Pesquisa de Clima & 11 \\
\hline Puente-Palacios (2002) & $\begin{array}{l}\text { Conceitos e } \\
\text { Dimensões }\end{array}$ & 1 \\
\hline Puente-Palacios e Freitas (2006) & $\begin{array}{l}\text { Conceitos e } \\
\text { Dimensões }\end{array}$ & 2 \\
\hline Puente-Palacios, Pacheco e Severino (2013) & Pesquisa de Clima & 12 \\
\hline Rocha et al. (2013) & Cultura e Clima & 3 \\
\hline Rueda, Baptista, Cardoso e Raad (2013) & $\begin{array}{l}\text { Conceitos e } \\
\text { Dimensões }\end{array}$ & 3 \\
\hline Thumim e Thumim (2011) & Pesquisa de Clima & 13 \\
\hline Toro $(2001)$ & Pesquisa de Clima & 14 \\
\hline $\begin{array}{l}\text { Sá, Mendes, Bispo, Telmo, Lacerda e Alves } \\
(2006)\end{array}$ & Cultura e Clima & 4 \\
\hline Schneider e Reichers (1986) & $\begin{array}{l}\text { Conceitos e } \\
\text { Dimensões }\end{array}$ & 4 \\
\hline Schneider et al. (2012) & Cultura e Clima & 5 \\
\hline Souza $(1980)$ & Pesquisa de Clima & 15 \\
\hline Villardi, Ferraz e Dubeux (2011) & Pesquisa de Clima & 16 \\
\hline Wang e Hsieh (2013) & Pesquisa de Clima & 17 \\
\hline
\end{tabular}

Fonte: Elaborado pelos autores.

A partir da Tabela 1, observa-se que houve a seleção de vinte e oito (28) artigos, contendo quatro (4) artigos que discutem os conceitos e dimensões de Clima Organizacional, cinco (5) artigos que discutem a cultura e o Clima 
Organizacional, dezessete (17) artigos sobre pesquisas e Clima Organizacional e um (1) artigo envolvendo a questão do clima e da inovação. Foram consultados periódicos científicos de alta reputação, envolvendo base de dados brasileira e internacional para fins de análise a partir da pesquisa bibliográfica.

\section{RESULTADOS E DISCUSSÃO}

As próximas subseções resgatam as principais pesquisas a respeito do Clima Organizacional que serão confrontadas neste artigo, com o intuito de mostrar lacunas e possiveis contradições acerca do clima e seus fatores constituintes. As pesquisas selecionadas, por possuírem características contraditórias, contribuem para a desestruturação de um consenso fundamentador da formação do Clima Organizacional.

\section{Clima Organizacional e desenvolvimento enquanto construto}

O construto de Clima Organizacional vem sendo utilizado de formas diversas pelos estudos acadêmicos, especialmente nas áreas de Gestão de Pessoas e da Psicologia Organizacional, da qual se originou. Assim, é possivel conceber o alvorecer da conceituação desse construto a partir dos estudos de Elton Mayo, realizados na unidade de Hawthorne da Western Eletric Company em 1927, que trouxeram as primeiras contribuições, as quais relacionaram desempenho no trabalho a diversos fatores ambientais da organização, incluindo os fatores sociais (Mayo, 1933). Dentre esses fatores sociais, podem-se destacar a integração entre os empregados e os gestores, a socialização e o bom tratamento dos empregados pelos chefes, o que implicaria em um Clima Organizacional diferenciado frente às empresas tayloristas da época de Mayo (1933).

Os estudos de clima se propagaram a partir da década de 1970, observados na área da Psicologia Industrial, cujo foco permeava as diferenças individuais dos colaboradores. Porém, foi com a explosão de estudos de Cultura Organizacional, a partir dos anos 1980, que a ideia de Clima Organizacional tomou forma mais densa e se ampliou para uma análise relativamente mais completa e complexa do ambiente organizacional. A elucidação do Clima Organizacional como uma pesquisa voltada para grupos ou organizações foi um importante passo para as pesquisas de clima, contudo, estudos focados no âmbito individual ainda estão presentes, aplicados principalmente pelos pesquisadores de Clima Psicológico, não sendo este, porém o foco deste ensaio (Schneider et al., 2012).

Neste interim, observa-se uma diversidade conceitual de elementos e fatores utilizados para mensurar este construto, não havendo uniformidade e concordância 
entre eles (Patterson et al., 2005; Bispo, 2006; Puente-Palacios e Freitas, 2006; Thumim e Thumim, 2011; Schneider et al., 2012; Bernstrøm et al., 2013; PeñaSuares et al., 2013, e Rocha et al., 2013).

As formações dos conjuntos de elementos constitutivos do construto Clima Organizacional não são igualmente tratadas pelos pesquisadores do tema, inclusive com a utilização de construtos superpostos na mensuração de Clima Organizacional, como Cultura Organizacional, Comprometimento, Liderança, Satisfação, e outros. De acordo com Nakata, Veloso, Fischer e Dutra (2009), essa mistura de construtos pode gerar vieses de mensuração.

A diferenciação entre Clima Organizacional e Clima Psicológico é uma das questões que gera desencontros no campo conceitual. Depois de muitas discussões e investigações, definiu-se que o Clima Organizacional é composto por elementos cognitivos, apresentando aspectos particulares do trabalho percebidos e partilhados pelos trabalhadores, enquanto o Clima Psicológico é constituído por elementos afetivos, identificando o significado da ligação individual do trabalhador (Martins, 2008).

Tendo isto posto, Martins (2008) traz também outra contradição em que alguns autores tratam Cultura Organizacional e Clima Organizacional como similares. Enquanto a Cultura Organizacional se refere a um construto mais duradouro, amplo e profundo, o qual se mostra mais voltado para a compreensão e compartilhamento de regras e valores que permeiam a organização e influenciam os comportamentos dos colaboradores, o Clima Organizacional envolve alguns elementos da cultura e está relacionado ao retrato momentâneo das impressões de uma determinada organização. Portanto, o clima estaria contido na cultura (Martins, 2008).

Neste sentido, Puente-Palacios (2002) apresenta essa concepção de que clima e cultura são semelhantes devido ao fato deles serem oriundos de um mesmo cenário que é a organização, contudo deixa claro que clima e cultura não se constituem em um mesmo fenômeno. Ainda que o Clima Organizacional seja composto de elementos comuns a de outros fenômenos, tais como satisfação, cultura, comprometimento entre outros, a presença ou ausência destes elementos não é o que define o construto, mas a organização e as relações entre os elementos que trazem particularidade ao fenômeno (Puente-Palacios, 2002).

Em relação a testes empíricos a respeito da correlação entre os elementos dos construtos de Clima Organizacional e Cultura Organizacional, os modelos de Clima Organizacional de Kolb (1978) e do modelo cultural de valores competitivos de Quinn 
(1984) fazem esta correlação e mostraram que a cultura não determina o clima, conforme demonstrado por Sá et al. (2006).

Assim, o Clima Organizacional tem sido conceituado, por exemplo, como "percepções compartilhadas que os membros desenvolvem através das suas relações com as politicas, as práticas e os procedimentos organizacionais tanto formais quanto informais” (Toro, 2001, p. 33). Para Koys e DeCotiis (1991, p. 266), trata-se de um "fenômeno perceptual duradouro, construído com base na experiência, multidimensional e compartilhado pelos membros de uma unidade da organização, cuja função principal é orientar e regular os comportamentos individuais de acordo com os padrões determinados por ela". Schneider e Reichers (1983) apresentam uma conceituação de clima como percepções compartilhadas dos funcionários sobre as práticas, procedimentos e eventos organizacionais, sendo estas percepções consideradas principalmente descritivas em vez de avaliativas ou afetivas.

Koys e DeCotiis (1991) valeram-se da definição de Schneider e Reichers (1983) para fundamentar seus estudos, não considerando fatores ou dimensões no instrumento de Clima Organização com características avaliativas e/ou afetivas. Contudo, diversos autores têm se utilizado de percepções dos colaboradores de caráter avaliativo ou afetivo para mensurar esse construto conforme analisado na próxima subseção.

\section{Dimensões constituintes do Clima Organizacional}

Segundo Patterson et al. (2005), o número de dimensões constituintes do clima proliferou durante os anos, causando confusão e travando o progresso teórico. Schneider et al. (2012) creditam essa confusão teórica ao elevado número de escalas produzidas, o que mostra a importância da aplicação do Clima Organizacional para os Estudos Organizacionais e a Gestão de Organizações, e simultaneamente a difusão e a falta de uniformidade quanto aos instrumentos de mensuração do Clima Organizacional.

Campbell, Dunnette, Lawler e Weick (1970) identificaram quatro dimensões comuns no Clima Organizacional que são: autonomia; grau de estrutura aplicada à situação; orientação para recompensa; e consideração, cordialidade e suporte. Contudo, com a proliferação das escalas de clima e com o número de dimensões que surgiram, tornou-se cada vez mais dificil de sistematizá-las, o que culminou na ausência de parametrização.

Neste contexto, dimensões pouco usuais como "Futebol" e "Convivência Familiar" vistas em Bispo (2006), como também a sobreposição de construtos como 
"Liderança" e "Satisfação" vistos em Del Campo (2013) e em Pimenta, El Aouar e Oliveira (2012), "Treinamento" visto em Patterson et al. (2005), que por si só constituem uma área de investigação, fortalecem ainda mais a argumentação deste artigo, que remete o Clima Organizacional à metáfora do mostro de Frankenstein, em que a formação do construto depende de partes e/ou da totalidade de outros construtos. A tabela 2 apresenta as principais semelhanças que fortalecem $o$ processo de analogia mediante metáfora.

Tabela 2. Similaridades metafóricas entre o construto clima organizacional e o monstro de Frankenstein.

\section{Clima Organizacional}

\begin{tabular}{ll}
\hline $\begin{array}{l}\text { É um construto multifacetado, formado a } \\
\text { partir de outros construtos. }\end{array}$ & $\begin{array}{l}\text { É uma criação a partir de partes de outros } \\
\text { seres humanos. }\end{array}$ \\
$\begin{array}{l}\text { É um construto forte com vida própria, de } \\
\text { dificil definição. }\end{array}$ & $\begin{array}{l}\text { É um ser artificial, com vida própria e } \\
\text { independente e que não possui uma } \\
\text { identidade. }\end{array}$ \\
\hline $\begin{array}{l}\text { É um construto mensurado de várias } \\
\text { maneiras, a partir de perspectivas }\end{array}$ & $\begin{array}{l}\text { É um ser de elevadas dimensões, alto, forte } \\
\text { e robusto, que não pode ser definido apenas } \\
\text { descritivas e racionais e avaliativas e }\end{array}$ \\
$\begin{array}{l}\text { como selvagem e cruel, pois possui também } \\
\text { um lado humano e sentimental. }\end{array}$ \\
\hline $\begin{array}{l}\text { Suas dimensões e indicadores são diversos } \\
\text { e podem mudar de acordo com a }\end{array}$ & $\begin{array}{l}\text { Suas atitudes dependem do contexto, } \\
\text { podendo ser extremamente violento (até }\end{array}$ \\
organização a ser analisada. & $\begin{array}{l}\text { mesmo em relação ao seu criador) ou } \\
\text { mesmo capaz de amar. }\end{array}$ \\
\hline $\begin{array}{l}\text { É um construto com risco de banalização e } \\
\text { crítica no mundo gerencial, visto como mera } \\
\text { pesquisa sem implicações em termos de }\end{array}$ & $\begin{array}{l}\text { É um ser estigmatizado como uma } \\
\text { aberração, sem utilidade e necessidade de } \\
\text { viver; mas que no fundo anseia por sua }\end{array}$ \\
\hline
\end{tabular}

Fonte: Elaborado pelos autores.

Portanto, os maiores esforços da análise deste estudo bibliográfico estão focados neste aspecto metafórico e para evidenciar, destacam-se alguns trabalhos desenvolvidos no Brasil que elaboram e/ou aplicam escalas de avaliação de Clima Organizacional para serem utilizadas em surveys, são eles: escalas de Bispo (2006), Martins (2008), Villardi, Ferraz e Dubeux (2011), Pimenta et al. (2012), PuentePalacios, Pacheco e Severino (2013), onde foram comparados as dimensões e os conceitos utilizados, conforme a Tabela 3.

Assim, a tabela 3 apresenta estes trabalhos e os aspectos: o principal conceito de clima utilizado, nome da escala utilizada quando citada, a quantidade de dimensões ou fatores e o objetivo do trabalho. 
Tabela 3. Conceito principal, nome da escala, quantidade de fatores e objetivos dos trabalhos analisados.

\begin{tabular}{|c|c|c|c|c|}
\hline Trabalho & Conceito principal & $\begin{array}{l}\text { Nome da } \\
\text { Escala }\end{array}$ & Objetivo & $\begin{array}{l}\text { Quantidade } \\
\text { de Dimensões } \\
\text { ou Fatores }\end{array}$ \\
\hline $\begin{array}{r}\text { Bispo } \\
(2006)\end{array}$ & $\begin{array}{l}\text { Clima Organizacional como } \\
\text { indicador do grau de satisfação } \\
\text { dos membros de uma empresa, em } \\
\text { relação a diferentes aspectos da } \\
\text { cultura ou realidade aparente da } \\
\text { organização (Coda, 1993). }\end{array}$ & - & $\begin{array}{l}\text { Elaboração de } \\
\text { um novo } \\
\text { modelo de } \\
\text { pesquisa de } \\
\text { Clima } \\
\text { Organizacional }\end{array}$ & 20 \\
\hline $\begin{array}{l}\text { Martins } \\
(2008)\end{array}$ & $\begin{array}{l}\text { Clima Organizacional consiste em } \\
\text { percepções compartilhadas que os } \\
\text { membros desenvolvem através das } \\
\text { suas relações com as politicas, as } \\
\text { práticas e os procedimentos } \\
\text { organizacionais tanto formais } \\
\text { quanto informais (Toro, 2001). }\end{array}$ & $\begin{array}{l}\text { Escala de } \\
\text { Clima } \\
\text { Organizac } \\
\text { ional- } \\
\text { ECO }\end{array}$ & $\begin{array}{l}\text { Elaboração de } \\
\text { uma Escala de } \\
\text { Clima } \\
\text { Organizacional }\end{array}$ & 5 \\
\hline $\begin{array}{l}\text { Villardi, } \\
\text { Ferraz e } \\
\text { Dubeux } \\
(2011)\end{array}$ & $\begin{array}{l}\text { Conjunto de percepções, conceitos } \\
\text { e sentimentos que as pessoas } \\
\text { compartilham a respeito da } \\
\text { organização e que afetam, de } \\
\text { maneira positiva ou negativa, a } \\
\text { forma como as pessoas ou grupos } \\
\text { se relacionam no ambiente de } \\
\text { trabalho, seu comprometimento e } \\
\text { desempenho (Souza, 1980). }\end{array}$ & - & $\begin{array}{l}\text { Elaboração de } \\
\text { uma } \\
\text { metodologia } \\
\text { para realização } \\
\text { de diagnóstico } \\
\text { de Clima } \\
\text { Organizacional }\end{array}$ & 9 \\
\hline $\begin{array}{l}\text { Pimenta, } \\
\text { El Aouar } \\
\text { e Oliveira } \\
(2012)\end{array}$ & $\begin{array}{l}\text { Percepção generalizada que o } \\
\text { indivíduo forma da organização, e } \\
\text { que é resultante de experiências } \\
\text { vivenciadas por ele neste ambiente } \\
\text { (Schneider e Barlett, 1970, como } \\
\text { citado em Pimenta et al., 2012). }\end{array}$ & - & $\begin{array}{l}\text { Avaliação do } \\
\text { clima } \\
\text { organizacional } \\
\text { em uma } \\
\text { instituição } \\
\text { pública } \\
\text { dedicada à } \\
\text { pesquisa } \\
\text { tecnológica. }\end{array}$ & 7 \\
\hline $\begin{array}{l}\text { Puente- } \\
\text { Palacios } \\
\text { et al. } \\
(2013)\end{array}$ & $\begin{array}{l}\text { Fenômeno perceptual duradouro, } \\
\text { construído com base na } \\
\text { experiência, multidimensional, } \\
\text { compartilhado pelos membros de } \\
\text { uma unidade da organização, cuja } \\
\text { função principal é orientar e } \\
\text { regular os comportamentos } \\
\text { individuais de acordo com os } \\
\text { padrões determinados por ela. } \\
\text { (Koys e DeCotiis, 1991). }\end{array}$ & - & $\begin{array}{l}\text { Verificar o } \\
\text { impacto do } \\
\text { clima sobre o } \\
\text { estresse } \\
\text { relatado em } \\
\text { equipes de } \\
\text { trabalho }\end{array}$ & 4 \\
\hline
\end{tabular}

Fonte: Elaborado pelos autores. 
De antemão, pode-se elucidar que os autores da Tabela 2 apresentam uma variedade de definições de clima que se diferenciam, por exemplo, a partir da perspectiva adotada para delinear esse construto. Há autores que definem o Clima Organizacional a partir da percepção quanto às práticas de Gestão de Pessoas, numa perspectiva formal, descritiva e objetiva (Martins, 2008; Toro, 2001). Outros autores conceituam o Clima Organizacional a partir de uma perspectiva afetiva, subjetiva e avaliativa (Schneider e Barlett, 1970, como citado em Pimenta et al., 2012; Coda, 1993; Bispo, 2006; Villardi et al., 2011; Pimenta et al., 2012).

Conforme demonstrado na Tabela 2, percebem-se divergências e similaridades entre os conceitos principais utilizados. Em relação às semelhanças, o compartilhamento pelos colaboradores das percepções do ambiente organizacional aparece em todos os conceitos, exceto no de Coda (1993). Villardi et al. (2011) destacam que além das percepções, os conceitos e sentimentos dos colaboradores também devem ser capturados pelos pesquisadores de Clima Organizacional, o que implica notadamente em aspectos subjetivos e avaliativos do que meramente descritivos na hora de se mensurar esse construto.

Em relação aos aspectos do ambiente organizacional destacados nas conceituações, Coda (1993) enfatiza o "grau de satisfação dos colaboradores" como também os aspectos da "cultura da organização". Já Martins (2008) evidencia "políticas, práticas e os procedimentos organizacionais". Schneider e Barlett (1970) e Pimenta et al. (2012) apresentam de forma mais ampla quando trazem a análise da organização como um todo, assim como Koys e DeCotiis (1991), optando por uma análise multidimensional da organização.

Em relação à quantidade de fatores ou dimensões utilizadas nas escalas de clima observadas, também não existe consenso, o número de fatores ou dimensões não segue um padrão, cuja amplitude dos trabalhos avaliados vão de 4 a 20.

Conforme a pesquisa bibliográfica, as dimensões ou fatores constituintes do construto em pauta formam um considerável arcabouço de divergências entre os teóricos da área. Como forma de reforçar este aspecto, descreve as dimensões utilizadas pelos trabalhos analisados, em que se pode observar a diversidade de fatores utilizados sem que haja uma uniformidade.

\section{Dimensões/fatores e descrição das dimensões/fatores dos trabalhos analisados: Trabalho: Bispo (2006)}

1. Ambiente de trabalho: Estabelece o grau de relacionamento entre os colegas de trabalho, necessário para a realização das atividades individuais ou coletivas. 
2. Assistência aos funcionários: Estabelece o nível da assistência médica, dentária, hospitalar e social aos funcionários.

3. Burocracia: Avalia se este item está compativel com as atividades realizadas pelos funcionários.

4. Cultura organizacional: Avalia o nível de interferência que as tradições, práticas e costumes, adotados informalmente na empresa, exercem sobre os funcionários e suas atividades.

5. Estrutura organizacional: Mede o nivel de relacionamento e de capacitação dos elementos que compõem esta estrutura e sua interferência nas atividades realizadas pelos funcionários.

6. Nivel sociocultural: Procura estabelecer se os níveis intelectual, cultural e social dos funcionários estão de acordo com as necessidades inerentes às suas atividades.

7. Incentivos profissionais: Visam estabelecer o nivel de reconhecimento profissional dos funcionários.

8. Remuneração: Avalia se este item está de acordo com as atividades prestadas à empresa.

9. Segurança profissional: Avalia o risco de demissão sem motivo, percebido pelos funcionários.

10. Transporte casa/trabalho-trabalho/casa: Mede o nível de dificuldade encontrado para a locomoção entre a casa dos funcionários e a empresa e vice-versa.

11. Vida profissional: Estabelece o grau de identificação profissional dos funcionários com a empresa, tentando medir o nível de seu orgulho em relação à empresa e de seu sucesso profissional.

12. Convivência familiar: Procura avaliar o nível da convivência familiar dos funcionários, item necessário para uma boa produtividade nas atividades realizadas na empresa.

13. Férias e lazer: Avaliam o grau de satisfação dos funcionários com estes itens, os quais também são necessários para garantir uma boa produtividade.

14. Investimentos e despesas familiares: Procuram avaliar o nível do bem-estar proporcionado às famílias dos funcionários.

15. Política e Economia: Tentam avaliar o nível de interferência proporcionado por estes itens na motivação dos funcionários.

16. Saúde: Tenta avaliar a opinião dos próprios funcionários sobre suas respectivas saúdes física e mental, um dos itens de extrema importância e de dificil observação. 
17. Segurança Pública: Avalia o nível de influência deste item na vida diária dos funcionários.

18. Situação financeira: $\mathrm{O}$ fato de um funcionário ter uma boa remuneração não é suficiente para que ele tenha uma boa situação financeira. Este item tenta avaliar como está a situação financeira dos funcionários.

19. Time de futebol: Item que já foi comprovado cientificamente que tem influência sobre a produtividade dos funcionários, este item tenta medir, portanto, o nivel de interferência que os times de futebol exercem sobre a motivação e a produtividade dos funcionários.

20. Vida social: Avalia o nível de satisfação dos funcionários com este item.

\section{Trabalho: Martins (2008)}

21. Apoio da chefia e da organização: Suporte afetivo estrutural e operacional da chefia e da organização fornecido aos empregados no desempenho diário de suas atividades no trabalho.

22. Recompensa: Diversas formas de recompensa usadas pela empresa para premiar a qualidade, a produtividade, o esforço e o desempenho do trabalhador.

23. Conforto físico: Ambiente físico, segurança e conforto proporcionados pela empresa aos empregados.

24. Controle/pressão: Controle e pressão exercidos pela empresa e pelos supervisores sobre o comportamento e desempenho dos empregados.

25. Coesão entre colegas: União, vínculos e colaboração entre os colegas de trabalho.

\section{Trabalho: Villardi, Ferraz e Dubeux (2011)}

26. Conformidade com as normas: Sentimento de que existem regras, procedimentos, diretrizes e práticas administrativas que têm de ser seguidos embora tirem a liberdade de fazer o trabalho da forma mais adequada.

27. Trabalho em equipe: Sentimento de que a integração facilita o cumprimento dos objetivos propostos pela organização. O sentimento de que as áreas, os indivíduos e os grupos (setores) trabalham de forma complementar para o alcance dos objetivos da organização.

28. Padrões de desempenho: Sentimento de que na organização enfatiza-se o desempenho com qualidade e produtividade superiores, inclusive estabelecendo metas estimulantes para si mesma e transmitindo às pessoas a importância do comprometimento com estas metas. 
29. Reconhecimento: Sentimento de que as pessoas são reconhecidas e recompensadas por um bom trabalho e de que, quando algo sai errado, não são ignoradas, criticadas ou punidas.

30. Clareza organizacional: Sentimento de que os objetivos estão definidos claramente e são comunicados com transparência e de que não são desordenados, confusos ou nebulosos.

31. Confiança e apoio interpessoal: Sentimento de que a boa relação entre as pessoas (pares, subordinados e superiores hierárquicos) é valorizada; que as pessoas acreditam umas nas outras, respeitam e oferecem apoio uns aos outros. O sentimento de que boas relações profissionais para realizar o trabalho prevalecem entre as pessoas no ambiente de trabalho.

32. Liderança: Sentimento de que a organização não é dominada nem dependente de poucos indivíduos. Quando surge a necessidade de liderança, as pessoas se sentem em liberdade de aceitar papéis de liderança.

33. Formação gerencial: Sentimento de que na organização a liderança é exercida por gestores previamente preparados para a atuação gerencial.

34. Impacto do trabalho: Sentimento de que na organização o trabalho realizado está efetivamente auxiliando e que está fazendo diferença.

\section{Trabalho: Pimenta, El Aouar e Oliveira (2012)}

35. Conformidade com as Normas: O grau em que os membros sentem que existem muitas regras, procedimentos, diretrizes e práticas que têm de ser seguidas, tirando-lhes a liberdade de fazer o trabalho como eles acham que o mesmo deveria ser realizado.

36. Responsabilidade: $\mathrm{O}$ grau em que a organização atribui responsabilidades aos seus membros, concedendo-lhes autonomia para tomar decisões e resolver problemas, sem ser preciso verificar com seus superiores, cada etapa.

37. Padrões de desempenho: A ênfase que a organização coloca na qualidade do desempenho e na produção elevada, incluindo o grau em que os membros da organização sentem que a entidade estabelece objetivos estimulantes, comunicando-lhes o comprometimento com os mesmos.

38. Recompensa: $O$ grau em que os membros sentem que também são reconhecidos e recompensados por um bom trabalho, e não apenas criticados ou punidos quando algo sai errado.

39. Clareza Organizacional: O sentimento entre os membros de que as coisas estão bem organizadas e os objetivos estão claramente definidos, ao invés de serem desordenados, confusos e caóticos. 
40. Apoio e Calor Humano: O sentimento de que a amizade é uma norma valorizada na organização; os membros confiam uns nos outros e oferecem, entre si, apoio mútuo. O sentimento de que boas relações prevalecem no ambiente de trabalho.

41. Liderança: O grau em que a organização reconhece e estimula a liderança dos membros realmente qualificados. Os indivíduos sentem-se em liberdade para assumir papéis de liderança e são recompensados por uma liderança bem sucedida.

\section{Trabalho: Puente Palácios et al. (2013)}

42. Promoção, recompensa e benefícios: Não descrito no original

43. Relacionamento com os pares: Não descrito no original

44. Características da tarefa: Não descrito no original

45. Relacionamento com a chefia: Não descrito no original

Observa-se, por exemplo, que a escala de Bispo (2006) é a única que apresenta dimensões que tratam de fatores externos à organização, tais como "vida social", "time de futebol", "política e economia", "segurança pública", entre outras. Neste sentido, Koles e Kondath (2015) indicam a influência de fatores externos de caráter sociocultural no clima organizacional, evidenciando esse aspecto por meio de pesquisa em empresas de Portugal, Índia e Hungria. Dentre as escalas apresentadas, a de Bispo (2006) é a que mais se diferencia em ousadia e amplitude no que tange aos fatores ou dimensões que a compõem.

No total, dos cinco trabalhos analisados, somam-se 45 dimensões apresentadas, das quais apenas 15 se repetem, havendo pouca evidência na utilização padronizada de fatores de mensuração do Clima Organizacional.

\section{As dimensões comuns aos trabalhos são:}

1. Dimensões ligadas ao relacionamento interpessoal entre colaboradores apoio e calor humano, coesão entre colegas, confiança e apoio interpessoal e relacionamento com os pares, que aparecem em quatro trabalhos.

2. Clareza em relação aos objetivos organizacionais, regras, transparência na comunicação no sentido de não ser confusa e desordenada. Esta dimensão foi utilizada em dois trabalhos, inclusive com a mesma terminologia: Clareza Organizacional.

3. Conformidade com as normas e diretrizes estabelecidas para realização do trabalho. Essa dimensão foi utilizada em dois trabalhos, inclusive com a mesma terminologia: Conformidade com as Normas. 
4. Aspectos ligados ao relacionamento com a chefia - liderança, relacionamento com a chefia. Essa dimensão foi utilizada em três trabalhos.

5. Padrões de desempenho do empregado - significa que a organização se preocupa em estabelecer metas e estimular o comprometimento do empregado. Essa dimensão aparece em dois trabalhos.

6. Sentimento por parte dos funcionários de que são recompensados por seu desempenho-a recompensa. Essa dimensão aparece em dois trabalhos, inclusive com a mesma terminologia.

Observa-se também a questão da sobreposição de construtos, como a "Liderança" que é comum nos trabalhos de Villardi et al. (2011), Pimenta et al. (2012), Puente-Palacios et al. (2013), ou "Cultura Organizacional" em Bispo (2006), "Formação Gerencial" em Villardi et al. (2011). Esses construtos, apresentados nessas escalas como dimensões, necessitariam de uma série de indicadores que ampliariam sobremaneira o instrumento, inviabilizando sua operacionalização. Seria o mesmo que tentar medir um construto não por meio de dimensões e indicadores, mas sim por meio de outros construtos que levariam a outros temas e outras perspectivas.

Na tentativa de resolver essa questão de redundância de construtos dentro das escalas de Clima Organizacional, Puente-Palacios e Freitas (2006) e Koys e DeCotiis (1991) se apoiam em uma definição do construto de clima como uma descrição objetiva de eventos e práticas organizacionais percebidas, em que dimensões com características afetivas e avaliativas como satisfação e comprometimento não poderiam constituir dimensões desse construto, uma vez que são fenômenos diferenciáveis. A partir disso, os autores sugerem um construto intitulado Clima Social Organizacional, que contribui no sentido de reduzir as dimensões de Clima Organizacional, retirando as dimensões de caráter afetivo e avaliativo, com dimensões que enfoquem mais as relações interpessoais.

Contudo, a diversidade e complexidade de conceitos e escalas acerca do construto de Clima Organizacional parecem indicar a dificuldade em padronizar ou reduzir as suas dimensões constituintes. As sugestões de Puente-Palacios e Freitas (2006) embora interessantes e válidas, poderiam também excluir construtos de caráter afetivos e avaliativos nas escalas de clima, tais como comprometimento e satisfação, que seriam relevantes para a intervenção gerencial no ambiente organizacional.

Observa-se que as pesquisas e diagnósticos de clima somam-se construtos diversos (satisfação, comprometimento, liderança, entre outros) de acordo com a 
necessidade e peculiaridade de cada objeto de pesquisa, que neste caso são as organizações, permitindo um retrato, a partir de um corte temporal, para ações gerenciais pontuais. Nesse aspecto, o construto Clima Organizacional talvez seja o mais situacional dos construtos dos Estudos Organizacionais. Neste ponto, a metáfora de Frankenstein encaixa-se ao tema, onde os instrumentos de mensuração de clima são formados com indicadores de outros construtos, assim como o referido monstro para que o mesmo tenha vida e funcionalidade. Além disso, outro ponto a ser destacado é a diversidade das dimensões, considerando as 45 utilizadas, sendo 36 delas diferentes, isso demonstra que além das pesquisas de clima assemelharemse à metáfora utilizada, tem-se um construto de grande magnitude (monstro) diferente para cada instrumento utilizado.

Apesar dessas divergências, o Clima Organizacional tem sido o preferido pelos gestores, devido ao fato de proporcionar uma medida que está relacionada à produtividade individual e da organização, qualidade do trabalho, qualidade de vida das pessoas dentro da organização (Martins, 2008; Bernstrøm, Lone, Bjørkli, Ulleberg e Hoff, 2013; Rueda, Baptista, Cardoso e Raad, 2013), e inovação (Imran, Saeed, Anis-Ul-Haq e Fatima, 2010). É um construto que exprime um estado momentâneo da organização, a partir da visão dos empregados, avaliando seus comportamentos individuais ou de um comportamento determinado no ambiente de trabalho, podendo ser modificados a partir de seu levantamento sistemático (Asif, 2011).

Contudo, pesquisas científicas pertinentes às ações pós-pesquisa de clima organizacional, ainda são de pouca ocupação dos pesquisadores da área conforme apresentado por Oliva, Falchi e Falchi, (2007), que inclusive é um dos poucos trabalhos que analisam as ações da empresa após levantamento do clima organizacional. A grande parte das pesquisas estão relacionadas à métodos de diagnósticos de clima, ensaios teóricos e/ou correlação de clima organizacional com algum aspecto da organização (Oliva et al., 2007), tais como: mutismo (Wang e Hsieh, 2013), cultura organizacional (Kolb, 1978; Quinn, 1984; Sá et al., 2006), inovação (Imran et al., 2010), estresse (Puente-Palacios et al., 2013), qualidade de vida (Rueda et al., 2013), dentre outros.

\section{CONSIDERAÇÕES FINAIS}

O construto do clima engendra elementos constituintes diversos e contraditórios por natureza. Este artigo mostrou que apesar das inúmeras tentativas de uniformizar e mesmo padronizar as definições e escalas de clima organizacional, ainda permanece a falta de consenso e as divergências nas formas de se mensurar 
esse construto. Este artigo contribuiu no sentido de mapear e apresentar essas divergências, apresentando lacunas e investigando a natureza desse construto.

Do ponto de vista gerencialista, trata-se de uma ferramenta de gestão para servir de instrumento de diagnóstico organizacional. Contudo, considera-se que o clima parece ser eficientemente mensurado quando contêm dentro de si construtos de ordem avaliativa, afetiva e subjetiva (tais como comprometimento e satisfação no trabalho, dentre outros) e descritiva, racional e objetiva (tais como descrição de políticas e práticas de remuneração e procedimentos, etc.).

Apesar das divergências conceituais, como também nas dimensões envolvidas e destacadas por cada autor, pode-se observar a relevância desse construto, a partir das inúmeras abordagens que o permeiam. Desde as noções de proximidade à Cultura Organizacional de Puente-Palacios e Freitas (2006), até as ideias de Schneider e Reichers (1983) que observam o Clima Organizacional como percepções compartilhadas que possuem caráter descritivo, ao invés de afetivo, consolidando metaforicamente o construto Clima Organizacional como a união de pedaços para a formação de um Frankenstein.

Portanto, este artigo alcançou o seu objetivo, pois a análise da produção acadêmica sobre o clima organizacional por meio da pesquisa bibliográfica mostrou que:

a) O Clima organizacional não é tratado consensualmente pelos pesquisadores;

b) Não parece haver consenso quanto às dimensões do construto de Clima organizacional, o que diversifica as escalas de mensuração;

c) Os autores divergem quando a natureza do construto de clima, pois alguns o tratam como um construto objetivo e descritivo e outros autores o tratam de modo avaliativo e afetivo;

d) A multidimensionalidade do Clima Organizacional confere flexibilidade às dimensões que podem ser personalizadas de acordo com a empresa e sua realidade;

e) As comparações em pesquisas de Clima Organizacional são dificultadas pela falta de uniformidade das escalas;

f) Não existe uma corrente de autores que consegue impor sua visão de Clima Organizacional sobre as demais, o que demonstra a difusão do conceito;

g) O fato da palavra Clima remeter a situações cotidianas e banais como meteorologia ou atmosfera contribui para a dificuldade de consolidar uma definição científica em sua origem. 
Deste modo, as divergências provenientes das diferentes visões sobre o Clima Organizacional viabilizam pesquisas cada vez mais inovadoras. A metáfora de Frankenstein se preserva neste caso, pois, a criatura, mesmo feita por partes desconexas, desprovida de um senso único, e desenvolvida a partir de indagações reflexivas, ainda se mostra capaz de fazer o mesmo que o Clima Organizacional, que é sobreviver.

\section{REFERÊNCIAS}

Asif, F. (2011). Estimating the impact of Denison's (1996), What is the difference between organizational culture and organizational climate?: A native's point of view on a decade of paradigm wars. Journal of Business Research, 64(5), 454-459.

Bernstrøm, V. H., Lone, J. A., Bjørkli, C. A., Ulleberg, P., e Hoff, T. (2013). Assessing a Norwegian translation of the organizational climate measure. Psychological Reports Human Research and Marketing, 112(2), 390-407.

Bispo, C. A. F. (2006). Um novo modelo de pesquisa de clima organizacional. Produção, 16(2), 258-273.

Campbell, J. P., Dunnette, M. D., Lawler, E. E., e Weick, K. E. (1970). Managerial behavior, performance, and effectiveness. New York: McGraw Hill.

Coda, R. (1993). Estudo sobre clima organizacional traz contribuição para aperfeiçoamento de pesquisa na área de RH. Revista de Administração, 75.

Cornelissen, J. P., Oswick, C., Christensen, L. T., e Phillips, N. (2008). Metaphor in organizational research: Context, modalities and implications for research- introduction. Organization Studies, 29(1), 7-22.

Del Campo, M. G. (2013). Clima organizacional en la Editorial Ciencias Médicas a partir del análisis de dos de sus dimensiones. Revista Cubana de Salud Pública, 39(2), 242-252.

Denzin, N. K., e Lincoln, Y. S. (2006). O planejamento da pesquisa qualitativa: Teorias $e$ abordagens. Porto Alegre: Artmed.

Gil, A. C. (2009). Como elaborar projetos de pesquisa. São Paulo: Atlas.

Imran, R., Saeed, T., Anis-Ul-Haq, M., e Fatima, A. (2010). Organizational climate as a predictor of innovative work behavior. African Journal of Business Management, 4(15), 3337-3343.

Islan, G. (2011). Can the subaltern eat?: Anthropophagic culture as a Brazilian lens on postcolonial theory. Organization, 19(2), 159-180.

Kolb, D. A. (1978). Organizational psychology: An experimental approach. New Jersey: Prentice Hall.

Koles, B., e Kondath, B. (2015). Organizational climate in Hungary, Portugal and India: A cultural perspective. AI \& Society, 3O(2), 251-259.

Koys, D., e DeCotiis, T. (1991). Inductive measures of psychological climate. Human Relations, 44, 265-85.

Martins, M. C. F. (2008). Clima organizacional. In: M. M. M. Siqueira (Org.). Medidas do comportamento organizacional. Porto Alegre: Artmed.

Mayo, E. (1933). The human problems of an industrial civilization. New York: The Macmillan Company.

Nakata, L. E., Veloso, E. F. R., Fischer, A. L., e Dutra, J. S. (2009). Uso de pesquisas de clima organizacional no Brasil. Gestão Contemporânea (FAPA), 6, 45-68. 
Oliva, E. C., Falchi, W. S., e Falchi, K. S. (2007). Ações implementadas pós-pesquisa do clima organizacional na multibras S/A eletrodomésticos. Revista Científica Symposium, 5(2), 36-45.

Patterson, M. G., West, M. A., Shackleton, V. J., Dawson, J. F., Lawthom, R., Maitlis, S., Robinson, D. L., e Wallace, A. M. (2005). Validating the organizational climate measure: links to managerial practices, productivity and innovation. Journal of Organizational Behavior, 26(4), 379-408.

Peña-Suares, E., Muñiz, J., Campillo-Álvarez, A., Fonseca-Pedrero, E., e García-Cueto, E. Assessing organizational climate: Psychometric properties of the CLIOR Scale. Psicophema, 25(1), 137-44.

Pimenta, R. C. Q., El Aouar, W. A., e Oliveira, J. A. (2012). Clima organizacional em Instituto de Pesquisa Tecnológica. RaUnP, 4(2), 23-38.

Puente-Palacios, K. E. (2002). Abordagens teóricas e dimensões empíricas do conceito de clima organizacional. Revista de Administração, 37(3), 93-104.

Puente-Palacios, K. E., e Freitas, I. A. (2006). Clima organizacional: Uma análise de sua definição e de seus componentes. O\&S, 13(38), 45-57.

Puente-Palacios, K. E., Pacheco, E. A., e Severino, A. F. (2013). Clima organizacional e estresse em equipes de trabalho. Revista Psicologia: Organização e Trabalho, 13(1), 37-48.

Quinn, R. E. (1984). Applying the competing values approach to leadership: Towards an integrative model. In J.G. Hunt, R. Stewart, C.A. Schriesheim, e D. Hosking (Ed.) Managers and leaders: An international perspective. New York: Pergamon.

Rocha, L. C. S., Pelogio, E. A., e Añez, M. E. M. (2013). Cultura e clima organizacionais: Um estudo em indústrias de laticinios do Estado do Rio Grande do Norte. Gest Prod, 20(2), 455-468.

Rueda, F. J. M, Baptista, M. N., Cardoso, H. F., e Raad, A. J. (2013). Psicologia organizacional: Associação entre qualidade de vida e clima organizacional. Encontro Revista de Psicologia, 16(24).

Thumim, F. J., e Thumim, L. J. (2011). The meansurement and interpretation of organizational climate. The Journal of Psychology, 142(2), 93-109.

Toro, F. A. (2001). El clima organizacional: Perfil de empresas colombianas. Medellin: Cicel Ltda.

Sá, M. A. D., Mendes, N. M. D., Bispo, A. C. K. A., Telmo, F. A., Lacerda, S. C. G., e Alves, C. A. (2006). O espelho não tem duas faces: um estudo entre a cultura e clima organizacional na UFPB. Anais do Encontro Nacional da Associação Nacional de Pós-Graduação e Pesquisa em Administração, Salvador, BA, Brasil, 30.

Schneider, B., e Reichers, A. E. (1983). On the etiology of climates. Personnel Psychology, 36, 19-39.

Schneider, B., Ehrhart, M. G., e Macey, W. H. (2012). Organizational climate and culture. The Annual Review of Psychology, 64, 361-388.

Shelley, M. (2012). Frankenstein, or the modern Prometheus. New York: Sterling Publishing.

Souza, E. P. (1980). Percepção de clima conforme escalão hierárquico. Revista de Administração de Empresas, 20(4), 51-56.

Villardi, B. Q., Ferraz, V. N., e Dubeux, V. J. C. (2011). Uma metodologia para diagnóstico de clima organizacional: integrando motivos sociais e cultura brasileira com fatores do ambiente de trabalho do Poder Judiciário. Revista de Administração Pública, 45(2), 303-29.

Wang, Y. e Hsieh, H. (2013). Organizational ethical climate, perceived organizational support, and employee silence: A cross-level investigation. Human Relations, 66(6), 783-802.

Rev. Int. Investig. Cienc. Soc.

Vol. $11 \mathrm{n}^{\circ} 1$, julio 2015. pág. 35-54. 